\title{
Means to improve underground coal mine safety by automated control of methane drainage systems
}

\author{
Gabriel Bujor Babut ${ }^{1, *}$, Roland Iosif Moraru ${ }^{1}$, and Mihai Popescu-Stelea ${ }^{1}$ \\ ${ }^{1}$ University of Petrosani, Faculty of Mines, 332006 Petrosani, Romania
}

\begin{abstract}
Based on the critical analysis of the presently employed management of methane drainage systems operation in Jiu Valley collieries, the paper aims to assess the basic elements required to develop an automated monitoring and control system of these. The results obtained after studies and researches carried out also allowed formulating certain proposals regarding the modification of manual control procedures of methane drainage systems operation, in order to correlate them with the prescriptions of legislation requirements from countries having a well-developed mining industry. Putting in practice the mentioned proposals could have immediate and beneficial effects on increasing the methane drainage process efficiency, leading meanwhile to an improved working environment and, implicitly, to a higher level of occupational safety and health in Jiu Valley collieries.
\end{abstract}

\section{Introduction}

In a modern mine a methane drainage system should fulfill the following requirements, sometimes contradictory [1-2]:

- reducing the concentration of methane in ventilation airflows, by draining as much as high possible gas quantities before these are reaching the mine working's atmosphere;

- capturing a gas mixture with a high value calorific power needed for beneficiation purposes.

The management of methane drainage systems requires performing numerous and regular controls which enable programming interventions aimed at limiting the influence of operational anomalies that inevitably have repercussions on the methane concentration in the working environment of coal mines [3-5].

The automated monitoring and control of methane drainage systems, reliable and effective, is therefore currently an imperious necessity.

In this context, the paper aims to identify the elements necessary to develop an automatic management system functioning degassing plants, taking into account the special role they still play, both in terms of output and especially of workplace safety.

The development of procedures for monitoring and control at methane drainage facilities used in Jiu Valley coal basin was this was done through the studies and research carried out at the central methane stations from Lupeni, Paroseni and Livezeni collieries. A major role

\footnotetext{
* Corresponding author: gabriel_babut@yahoo.com
} 
in accomplishing in carrying out this research returned to the expertise gathered from discussions with a large spectrum of experts involved in the coal seams drainage operations (mine technical staff, researchers from the National Institute for Research and Development in Mine Safety and Protection to Explosion - INCD INSEMEX Petrosani, labor inspectors). The main aspect considered was the variation of parameters describing the methane drainage systems operation.

In formulating proposals and conclusions of the studies and research carried out in Jiu Valley collieries were taken into account, where appropriate, the observations made on the length of specialization and documenting stages made in coalfields from Poland, France, Russia and Czech Republic.

\section{Monitoring and control of methane drainage systems performed at underground drainage ducting network level. A critical analysis}

\subsection{Preliminary controls}

This kind of control refers to the checking, along the entire length of the drainage pipes, of the following issues:

- valves operation;

- water-gas-detritus separators state;

- location of any aspiration of air within the drainage piping.

While the, occupational safety and health (OS\&H) statutory requirements in force in Romania do not require to achieve this type of control, it is only performed sporadically [6]. To increase the efficiency of the coal degassing we propose to implement this type of control on daily basis, by qualified personnel according to a schedule set by the head of ventilation and OS\&H department of the mine.

\subsection{Methane concentration monitoring}

Romanian OS\&H regulation in force stipulate to determine the concentration of methane the following intervals: monthly, at the aprons and drainage locations (niches) and at drainage points coupled to the collector pipes; bimonthly at the measuring diaphragms of the drainage pipe route. The low frequency in the determination of the methane concentration does not allow a proper and effective of the methane drainage systems. Experience acquired worldwide recommend the determination of the methane concentration in drainage pipes to be carried out on daily basis, and in some cases the need for several measures during the same day is stipulated [7-8].

The allowed lowest methane concentration value in the main ducting network of central drainage systems is $30 \%$. In pipes linking the degassing locations to the main or secondary drainage pipes the allowed lowest methane concentration value is $20 \%$. While the present frequency imposed for methane measurements by the OS\&H regulations in force is not allowing to perform adequate adjustments of the system, we are further presenting the control and adjustment procedures involving daily measurements of this parameter.

If in the moment of methane concentration measurement, the value obtained is near the $30 \%$ limit, one will pursue to the methane-air mixture flow reduction, through the adjustment of the regulating valve. This operation is aimed at providing a methane concentration increase in the drained methane-air mixture.

After this adjustment is completed, a new control is performed. If the methane concentration did not exceeded $30 \%$ and the oxygen content equals or is higher than $7 \%$, 
the adjustment valve will be completely closed. If, contrarily, a significant increase is registered in the methane concentration simultaneously with a lower than $7 \%$ oxygen concentration, then the new parameter values will be recorded and the valve will be maintained in the same position.

The staff members involved in the control process will dispose permanently of the data representing the measurement results from the previous days. If the methane concentration value measured in day $\mathrm{N}$, compared to values measured in days $\mathrm{N}-1, \mathrm{~N}-2, \ldots$ are emphasizing a slow decrease trend, of a few percents per day, then the causes of this phenomenon can be one of those listed below:

- a barometric pressure increase, with a subsequent alteration of the gassy-dynamic regime;

- the depletion of the gas reservoir.

If, although this methane concentration decreases, this parameter's value is placed above the imposed limit (e.g. at values comprised between 45 - $50 \%$ ), this value will be recorded, but no adjustment operation will be required. Nevertheless, for that measuring station the frequency of controls will be increased (e.g. one measurement per working shift).

If a sudden methane concentration decrease is occurring from one day to another (having a magnitude of tenths of percents methane), an adjustment operation is required immediately.

The following cases can be identified:

- despite the sudden decrease, methane concentration remains above the regulated limit: in this situation the gas flow will be diminished, the reduction being proportional to the flow quantity value; after adjustment is completed, methane concentration and flow will be monitored on regular basis; if concentration is still decreasing, the flow will be further reduced and the previous procedure will be repeated; otherwise, namely in concentration stabilization conditions, the parameters values will be recorded and no further adjustment will be carried out;

- the sudden decrease of methane concentration brings this parameter in the vicinity of the regulated limit:

- if the source supplies a high gas quantity $\left(>500 \mathrm{~m}^{3} / \mathrm{h}\right)$ the flow will be consistently reduced and the methane and oxygen concentrations will be monitored; the previously described procedure will be applied;

- if the source supplies a high gas quantity $\left(100-200 \mathrm{~m}^{3} / \mathrm{h}\right)$, this source will be shut down; a visual control of the drainage pipe will be performed upstream the measuring station for detecting the potential air inleakages; based on the information provided by the staff members involved in the monitoring process, the drainage officer from the mine ventilation and OS\&H department will decide if certain adjustments should be done to mitigate the occurred situations.

\subsection{Gas flow determination}

Gas flow determination in the drainage pipes is done indirectly, employing standardized diaphragms. To simplify the gas flow measurements, the INCD INSEMEX Petrosani has elaborated nomographic charts for each kind of diaphragm.

Romanian OS\&H regulations in force are stipulating the compulsoriness of bimonthly determination of gas flows in the drainage locations and at the measuring nozzles on the drainage ducting route. Being that the drained gas flow represents one of the parameters determining the effective operation of the methane drainage system the aforementioned measurement frequency is inadequate [9]. For this reason, we propose the daily determination of gas flow in the drainage locations and at the measuring nozzles on the drainage ducting route.

Next there are presented the proposed control and adjustment procedures for the case of daily frequency gas flow measurement: 
- sudden increase of rough and net flow: this increase can be either triggered by a barometric pressure fall, or by the change of operational parameters of the drainage plant; this situation is rather favorable and do not requires any flow adjustment intervention;

- increase in the rough flow value only: if an increase in the rough flow value only is registered simultaneously with pressure decrease, there is a possibility that incidental inleakages occur through the drainage ducting; a visual control is needed upstream the measuring point;

- decrease of rough and net flow: as rule-of-thumb, a gas flow decrease is accompanied by a pressure fall; comparing the measured flow value with the previously determined values it can be emphasized a slow flow decrease trend, not followed by a high pressure drop; this situation is due to the drainage pipe impairment, or else, more probably, to the obstruction or shearing of the drainage borehole; if drainage operations in a production sector are involved then the pressure drop will be risen by opening the adjustment valve (respecting the guard of water-gas-detritus separator); a new measurement series will allow to assess the effects induced on the situation; if the presence of additional drainage possibilities arose, the water-gas-detritus separators will be shut off to apply the maximum available pressure drop; the adjustment valve will be reopened, while the main goal of drainage operation still is the methane concentration reduction in the underground atmosphere.

\subsection{Pressure drop determination}

According to the OS\&H regulations in force in Romania, pressure drop determination should be done bimonthly in the drainage locations and at the measuring nozzles on the drainage ducting route. The considerations mentioned for the case of methane concentration and gas flow measurements are also valid in the case of pressure drop determination in drainage pipes. For this reason we proposed for pressure drop also the measurement on daily basis.

The proposed control and adjustment procedures are the following:

- low variations of pressure drop: in the case of low pressure drop variations the variation of barometric pressure will also be determined, while they generally are in direct interdependence; no adjustment will be required in this situation;

- pronounced pressure drop increase: in this situation, the gas flow and the methane concentration will be also measured; if fluctuating gas velocity is detected, this emphasizes the presence of a water plug in the drainage pipeline; the status of water-gasdetritus separators will be checked, opening them at once if they were found closed; the adjustment valve will be partially shut down, to reduce pressure drop value; once the operational regime is stabilized, a new series of measurements will be performed and the need of other regulation/adjustment operation will be assessed; if the water plug was eliminated, the methane concentration is high and a margin of safety remains on handling the adjustment valve, then the valve can be reopened to obtain a further increase the pressure drop on the pipe;

- pronounced pressure drop decrease: the pronounced pressure drop decrease in the drainage pipe is generally accompanied by rough and net gas flow reduction; procedures to be applied are similar to those described in section 2.3 .

\subsection{Carbon monoxide concentration determination}

Romanian OS\&H regulation in force stipulate to determine the concentration of carbon monoxide monthly, only at the aprons and drainage locations (niches). Because the concentration of carbon monoxide can provide information for early detection of spontaneous 
combustion, we propose its measurement on regular basis. Similarly with the case of the other aforementioned parameters we propose the daily measurement of the carbon monoxide concentration.

For the specific conditions of the Jiu Valley collieries there were not determined the maximum allowable limits of the carbon monoxide concentration. The worldwide experience in the field of coal seam methane drainage indicates that the following limit values can be employed [10]: at drainage locations level - 90 ppm CO; at drainage aprons level - 45 ppm $\mathrm{CO}$.

These values can be also used in a first stage for the methane drainage systems operating in Jiu Valley coal basin, following that they will be further adapted to the specific geological and mining conditions met in this coal basin.

The proposed control and adjustment procedures are the following:

- slow carbon monoxide concentration increase: in this case, we consider a 2-3 ppm/day increase; if the carbon monoxide concentration is not near maximum allowable limit, no adjustment is required;

- fast carbon monoxide concentration increase: can be defined as an increase higher or equal to $10 \mathrm{ppm} / \mathrm{day}$; in this situation, two types of actions can be envisaged:

- partial closure of the adjustment valve, to decrease the applied pressure drop;

- in that measuring point the measurement frequency will be increased.

\subsection{Oxygen concentration determination}

Romanian OS\&H regulation in force do not stipulate the need to determine the oxygen concentration in the drainage network. Since the expertise acquired in countries with welldeveloped mining industry is highlighting that, besides the methane concentration, the oxygen concentration represents a main parameter determining the safe operation of the methane drainage system, we propose the introduction in the national OS\&H regulations of the compulsoriness of daily measurement of the oxygen concentration in the drainage locations and at the measuring nozzles on the drainage ducting route.

The maximum value of the oxygen concentration indicated in worldwide literature is $7 \%$ [10] and the control and adjustment procedures are synthesized bellow:

- slow oxygen concentration increase: by slow oxygen concentration increase it is understood a modification lower than one percent per day; if such an increase is recorded, the measuring frequency will be higher;

- fast oxygen concentration increase: the meaning of the notion of fast oxygen concentration increase is defined as a change with several percent's of the concentration, above the limit of $7 \%$, during one day period; in this case, in the first stage a visual inspection of the drainage pipes will be done, to detect a potential incidental air inleakage; furthermore, the adjustment valve will be partially closed to diminish the pressure drop exerted; if the oxygen concentration does not decrease below $7 \%$, the gas source should be shut down.

\subsection{Drained gas temperature determination}

Romanian and worldwide OS\&H regulation in force do not stipulate the need to determine the temperature of the drained gas. In these conditions, this parameter is measured only exceptionally. Because the temperature of the drained gas can provide information for early detection of spontaneous combustion, we propose its measurement on regular basis. 


\section{Controls at methane drainage plant level}

If the methane concentration in the exhaustion pipe (after the vacuum pump) decreases below $30 \%$, the operation of the methane drainage system is automatically shut down and an alarm signal is generated.

Romanian OS\&H regulation in force do not stipulate the need to determine the oxygen concentration at the drainage system's level. For the reasons mentioned in section 2.6, it is proposed to continuously measure and record the oxygen concentration and introducing the $7 \%$ value for automatic shutdown of the methane drainage system and generation of an alarm signal.

The central methane drainage system should include the following monitoring and control apparatus [6]:

- gas analyzer with continuous indication and recording of the extracted gas concentration;

- flow meter with continuous indication and recording of the extracted gas quantity;

- indicator and recorder vacuum-meter for pressure drop monitoring in the suction pipe;

- indicator and recorder manometer for pressure monitoring in the discharge pipe;

- indicator and recorder thermometers for gas temperature monitoring in the suction and discharge pipes, and for cooling water control;

- gas analyzer for automated control of methane concentration in the chamber containing the suction equipment and in the command room; it should be mounted in the highest location in which methane accumulation is possible.

\section{Assessment of elements required for developing automated monitoring and control methane drainage systems}

The analysis of the results of studies and research performed, combined with the proposals set in the previous sections allows to assess the main elements required for the development of an automated monitoring and control methane drainage systems [11-12]. These elements can be summarized as it follows:

- parameters to be determined and their variation range:

- methane concentration of drained gas:

- carbon monoxide concentration of drained gas:

- oxygen concentration of drained gas:

$0-100 \%$

0 - $300 \mathrm{ppm}$;

- differential pressure (for indirect flow measurement): $0-6000 \mathrm{~m}^{3} / \mathrm{h}$;

- absolute pressure in the drainage pipe: $0-10^{5} \mathrm{~Pa}$;

- drained gas temperature:

$0-120^{\circ} \mathrm{C}$.

- limit values for certain parameters (stipulated in OS\&H regulations in force or assessed based on experience acquired):

- methane concentration: if the methane concentration in the suction pipe (after the vacuum pump) decreases below $35 \%$ an alarm signal will be triggered; if the methane concentration in the suction pipe decreases below $30 \%$ the suction equipment will be automatically shut down; the minimum allowable methane concentration in the underground drainage pipes is $30 \%$; in the connection pipes between the drainage points and the main or secondary pipes, the minimum allowable methane concentration is $20 \%$;

- oxygen concentration: maximum allowable oxygen concentration is $7 \%$;

- carbon monoxide concentration: maximum allowable carbon monoxide concentrations are: at drainage locations level - 90 ppm; at drainage aprons level - 45 ppm. 
Table 1 summarizes the major abnormalities which can affect the normal operation of a methane drainage system and the variation pattern of the main parameters emphasizing these abnormalities.

Table 1. Potential abnormalities possible to occur in a methane drainage system's operation

\begin{tabular}{|c|c|c|c|c|c|c|c|c|c|c|c|}
\hline \multirow{2}{*}{ Specification } & \multicolumn{2}{|c|}{$\begin{array}{c}\mathbf{C H}_{4} \\
{[\%]}\end{array}$} & \multicolumn{2}{|c|}{$\begin{array}{c}\mathbf{O}_{2} \\
{[\%]}\end{array}$} & $\begin{array}{c}\text { CO } \\
{[\%]}\end{array}$ & \multicolumn{2}{|c|}{$\begin{array}{c}\text { Gas flow } \\
{\left[\mathbf{m}^{\mathbf{3}} / \mathbf{s}\right]}\end{array}$} & \multicolumn{2}{c|}{$\begin{array}{c}\text { Absolute } \\
\text { pressure } \\
{[\mathbf{P a}]}\end{array}$} & $\begin{array}{c}\text { Temperature } \\
{\left[{ }^{\circ} \mathbf{C}\right]}\end{array}$ \\
\hline & $\begin{array}{c}\downarrow \\
\text { fast }\end{array}$ & $\begin{array}{c}\downarrow \\
\text { slow }\end{array}$ & $\begin{array}{c}\uparrow \\
\text { fast }\end{array}$ & $\begin{array}{c}\uparrow \\
\text { slow }\end{array}$ & $\uparrow$ & $\begin{array}{c}\uparrow \\
\text { fast }\end{array}$ & $\begin{array}{c}\downarrow \\
\text { fast }\end{array}$ & $\begin{array}{c}\downarrow \\
\text { slow }\end{array}$ & $\uparrow$ & $\downarrow$ & $\uparrow$ \\
\hline $\begin{array}{c}\text { Drainage pipe rupture or } \\
\text { drainage borehole breakage } \\
\text { upstream the measuring } \\
\text { point }\end{array}$ & $\mathrm{X}$ & & $\mathrm{X}$ & & & $\mathrm{X}$ & & & $\mathrm{X}$ & & \\
\hline $\begin{array}{c}\text { Drainage pipe rupture } \\
\text { downstream the measuring } \\
\text { point }\end{array}$ & & & & & & & $\mathrm{X}$ & & $\mathrm{X}$ & & \\
\hline $\begin{array}{c}\text { Parallel mounted drainage } \\
\text { pipe rupture }\end{array}$ & & & & & & & $\mathrm{X}$ & & $\mathrm{X}$ & & \\
\hline Drainage pipe impairment & & & & & & & $\mathrm{X}$ & & & $\mathrm{X}$ & \\
\hline Water plug & & & & & & & $\mathrm{X}$ & & & $\mathrm{X}$ & \\
\hline $\begin{array}{c}\text { Spontaneous combustion } \\
\text { triggering }\end{array}$ & & & & & $\mathrm{X}$ & & & & & & \\
\hline $\begin{array}{c}\text { Total or partial shutdown } \\
\text { of the drainage system }\end{array}$ & & & & & & & $\mathrm{X}$ & & $\mathrm{X}$ & & \\
\hline Methane source depletion & & $\mathrm{X}$ & & $\mathrm{X}$ & & & & $\mathrm{X}$ & $\mathrm{X}$ & & \\
\hline
\end{tabular}

\section{Conclusions and proposals}

The critically analysis of control and adjustment procedures presently applied in methane drainage systems within Jiu Valley collieries let us emphasize that they do not allow an adequate and effective enough management of their operation.

The main findings imposing this conclusion are related to the low frequency of measurements (generally on monthly or bimonthly basis) and the lack of controls otherwise well established by regulations in countries with developed mining industry (e.g. oxygen concentration monitoring). Also, it should be mentioned that adjustment procedures are not precisely established, there necessity and ways to perform them being left to the expertise level of the staff members charged with drainage monitoring and management activities.

To set these drawbacks practical proposals concerning the introduction in the III ${ }^{\mathrm{rd}}$ Chapter - Mine drainage, from the $\mathrm{V}^{\text {th }}$ section of the Occupational Safety and Health Regulation in force at the National Hard Coal Company - Petrosani of certain provisions regarding:

- the compulsoriness of carrying out on daily basis the measurement of the methane drainage system's parameters;

- the compulsory oxygen concentration determination at drainage pipes network and methane drainage system's level;

- the compulsoriness of carrying out carbon monoxide concentration and temperature at all methane sources level (drainage locations, aprons etc), considering that monitoring these parameters is a valuable information source for early detection of spontaneous combustion.

At the same time, we developed the procedures of methane drainage system operational adjustment, considering the daily frequency of controls. 
Putting in practice the presented proposals is likely to generate a significant improvement of the hand powered control and adjustment procedures presently employed, with immediate beneficial consequence regarding the raise of coal methane drainage systems efficiency. Nonetheless, should be stated that the proposed control and adjustment procedures are based on the reliability of the human factor, raising a potential risk of inadequate assessment of the dynamic situation changes occurring, with direct negative impact on work safety. The uncertainty related to the error range brought by human operator, with all his limits and possible faults, constitutes an important drawback of the actual manually operated methane drainage systems.

Under these circumstances, beyond the identification of improvement possibilities of the present methane drainage systems operation, the analysis carried out allowed also to establish the elements converging to the development of an automated monitoring and control methane drainage systems, representing the initial step to the development of such a system.

\section{References}

1. E. Cichowski, Archives of Mining Sciences, 48 (1), 81 (2003)

2. E. Krause, K. Krzemień, Journal of Sustainable Mining, 13(2), 6 (2014)

3. C.Ö. Karacan, F.A. Ruiz, M. Cotè, S. Phipps, International Journal of Coal Geology, 86(2-3), 121 (2011)

4. F.N. Kissell, Handbook for methane control in mining, (U.S. Department of Health and Human Services, Public Health Service, Centers for Disease Control and Prevention, National Institute for Occupational Safety and Health, DHHS (NIOSH) Publication No. 2006-127, Information Circular 9486, Pittsburgh, PA: U.S., Accessed on 11 March 2017 at: https://www.cdc.gov/niosh/ mining/UserFiles/works/pdfs/2006-127.pdf, 2006)

5. R.I. Moraru, G.B. Babut, L.I. Cioca, Proceedings of the 13th SGEM GeoConference on Science and Technologies in Geology, Exploration and Mining, I, 731 (2013)

6. N.H.C.C., Occupational Safety and Health Regulation of National Hard Coal Company - Petrosani (in Romanian), National Hard Coal Company, Petrosani, Romania (2007)

7. J.M. Mutmansky, Guidebook on coalbed methane drainage for underground coal mines: White Paper, (U.S. Environmental Protection Agency, Washington, DC: U.S., 1999)

8. Q. Ye, Y. Pi, Z.Z. Jia, H.Z. Wang, Applied Mechanics and Materials, 295-298, 3023-3026 (2013).

9. N. Szlązak, M. Borowski, D. Obracaj, J. Swolkień, M. Korzec, Archives of Mining Sciences, 59(3), 655 (2014)

10. UNECE, Best practice guidance for effective methane drainage and use in coal mines, (U.N. Economic Commission for Europe, ECE Energy Series, No. 31, Geneva, Switzerland, Accessed on 11 March 2017 at: http://www.unece.org/fileadmin/DAM/energy/se/pdfs/cmm/pub/ BestPractGuide_MethDrain_es31.pdf, 2010)

11. G.B. Babut, R.I. Moraru, Proceedings of the $14^{\text {th }}$ SGEM GeoConference on Science and Technologies in Geology, Exploration and Mining, III, 71 (2014)

12. W. Dziurzynski, A. Krach, T. Palka, Archives of Mining Sciences, 54(2), 159 (2009) 